\title{
WHAT IS THE OBJECT OF THIS EXERCISE? \\ A MEANDERING EXPLORATION OF THE MANY MEANINGS OF OBJECTS IN MUSEUMS
}

\author{
ELAINE HEUMANN GURIAN
}

"W hy did the Serbs and Croats shell each other's historic sites when they had so little ammunition and these were not military targets?" I routinely ask my museum-studies graduate students this question when I lecture. "To break their spirit", is always the instantaneous answer. Museums, historic sites, and other institutions of memory, I would contend, are the tangible evidence of the spirit of a civilised society. And while the proponents of museums have long asserted that museums add to the quality of life, they have not understood (as the graduate students did when confronted by the example of war) how profound and even central that 'quality' was.

Similar examples reveal the relationship between museums and 'spirit' in sharp detail. Why did the Russians proclaim, one day after the Russian revolution had succeeded, that all historic monuments were to be protected even though they most often represented the hated czar and the church? Why did Hitler and Stalin establish lists of acceptable and unacceptable art and then install shows in museums to proclaim them while sending the formerly acclaimed, now forbidden, art to storage? Why did the Nazis stockpile Jewish material and force interned curators to catalogue and accession it, intending to create a museum to the eradicated Jews? Why, when I was in the rural mountains of the Philippines, was I taken to hidden closets that served as museums, curated by tribal members, holding the material of the tribe's immediate past, secreted from the dealers who were offering great sums for the same material?

In adversity it is understood, by antagonists and protagonists alike, that the evidence of history has something central to do with the spirit, will, pride, identity, and civility of people, and that destroying such material may lead to forgetting, broken spirits, and docility. This same understanding is what motivates cultural and ethnic communities to create their own museums in order to tell their stories, in their own way, to themselves and to others.

Yet neither the museum profession nor its sibling workers in the other storehouses of collective memory (archives, libraries, concert halls, and so forth), makes (nor, I would contend, understands) the case clearly about its institution's connectedness to the soul of civic life. In cities under duress you can hear the case being made better by mayors and governors. Dennis Archer, the mayor of Detroit, said recently while being interviewed on the radio, 'Detroit, in order to be a great city, needs to protect its great art museum, the Detroit Institute of Art.' It was Archer and his predecessor, Coleman Young, who championed and underwrote the latest incarnation of Detroit's Museum of African American History. And it was Teddy Kolik, the fabled former mayor of Jerusalem, who was the chief proponent of the creation of the Israel Museum (and who placed one of his two offices within the building). Mayors know why museums are important. Citizens, implicitly, do too. A recent survey in Detroit asked people to rate the importance of institutions to their city and then tell which they had visited. The Museum of African American History was listed very high on the important list and much lower on the "I have visited" list. People do not have to use the Museum in order to 
assert its importance or feel that their tax dollars are being well spent in its support.

The people who work in museums have collectively struggled over the proper definition and role of their institutions. Their struggle has been, in part, to differentiate museums from other near relatives - the other storehouses of collective memory. The resulting definitions have often centred on things - on objects and their permissible uses. I believe the debate has missed the essential meaning (the soul, if you will) of the institution that is the museum.

\section{OBJECTS ARE NOT THE HEART OF THE MUSEUM}

The following discussion will attempt to capture that soul by throwing light on the shifting role of museum objects over time. It will show how elusive objects are, even as they remain the central element embedded within all definitions of museums. This essay will also postulate that the definition of a 'museum object' and the associated practices of acquisition, preservation, care, display, study, and interpretation have always been fluid and have become more so recently. Objects did not provide the definitional bedrock in the past, although museum staff thought they did. I will show that museums may not need them any longer to justify their work.

But if the essence of a museum is not to be found in its objects, then where? I propose that the answer is in being a place that stores memories and presents and organises meaning in some sensory form. It is both the physicality of a place and the memories and stories told therein that are important. Further, I propose that these two essential ingredients - place and remembrances are not exclusive to museums. And, finally, I contend that the blurring of the distinctions between these institutions of memory and other seemingly separate institutions (like shopping malls and attractions) is a positive, rather than negative, development.

Not meaning to denigrate the immense importance of museum objects and their care, I am postulating that they, like props in a brilliant play, are necessary but alone are not sufficient. This essay points out something that we have always known intuitively: that the larger issues revolve around the stories museums tell and the way they tell them. When parsed carefully, the objects, in their tangibility, provide a variety of stakeholders with an opportunity to debate the meaning and control of their memories. It is the ownership of the story, rather than the object itself, that the dispute has been all about.

This essay suggests what museums are not (or not exactly) and, therefore, continues the dialogue about what museums are and what makes them important, so important that people in extremis fight over them.

\section{WHAT IS AN OBJECT?}

"Ah, but we have the real thing", museum professionals used to say when touting the uniqueness of their occupation. When I began in museum work, in the late 1960s and early 1970s, the definition of museums always contained reference to the object as the pivot around which we justified our other activities. ${ }^{1}$ Although there were always other parts of the definition, our security nonetheless lay in owning objects. With it came our privileged responsibility for the attendant acquisition, its preservation, safety, display, study, and interpretation. We were like priests and the museums our reliquaries.

The definition of objects was easy. They were the real stuff. Words were used like 'unique', 'authentic', 'original', 'genuine', 'actual'. The things that were collected had significance and were within the natural, cultural, or aesthetic history of the known world.

Of course, real had more than one meaning. It often meant 'one-of-a-kind', but it also meant 'an example of'. Thus, artworks were one-of-a-kind, but eighteenth-century farm implements may have been examples. Things made by hand were unique, but manufactured items became examples. In the natural history world, almost all specimens were examples but had specificity as to location found. Yet some 
could also be unique - the last passenger pigeon or the last dodo bird. Objects from both categories, unique and example, were accessioned into the collections. Museums owned the objects and took on the responsibility of preserving, studying, and displaying them.

Yet even within these seemingly easy categories there were variations. In asserting uniqueness (as in made-by-hand), specific authorship was associated with some objects, such as paintings, but not with others, most especially utilitarian works whose makers were often unknown. Some unique works were thought of as 'art' and some as 'craft'; with some notable exceptions, art was individualised as to maker but craft was not. This practice, which is now changing, made it possible to do research and mount shows of the work of particular artists in some, but not all, cultures.

\section{WHAT ARE COLLECTIONS?}

In the early 1970s the American Association of Museums (AAM) established an Accreditation Commission. As its members deliberated, they discussed whether groups of living things could be called collections and whether institutions that so 'collected' should be classified as museums. Heretofore, 'museums' were conserving things that had never been, or now were no longer, alive. The field debated if the living things in botanical gardens, fish in aquaria, or animals in zoos were 'collections'; if so, were those institutions, de facto, museums? It was decided that, yes, at least for funding and accreditation purposes, they were museums, and the living things they cared for were likewise to be regarded as collections, and hence objects. ${ }^{2}$

Yet there were other institutional repositories that cared for, protected, preserved, and taught about 'objects' but were not called museums nor necessarily treated by museums as siblings. Archives and libraries, especially rare-book collections, were considered related but not siblings even though some museum collections contain the identical materials. There were also commercial galleries and private and corporate collections that were considered by museum professionals to be different and outside the field, separated supposedly by an underlying purpose. A legal distinction of 'not-for-profit' was considered an essential part of the definition of a museum. It was clear that while objects formed the necessary foundation upon which the definition of a museum might rest, they were not sufficient in themselves.

\section{CAN NON-COLLECTING INSTITUTIONS BE MUSEUMS?}

The Accreditation Commission of the AAM next sought to determine if places that resembled collections-based museums but did not hold collections (i.e. places like not-forprofit galleries and cultural centres) were, for purposes of accreditation, also museums. In 1978, they decided that, in some instances, galleries could be considered museums because, like museums, they cared for, displayed, and preserved objects even though they did not own them. Ownership, therefore, in some instances, no longer defined museums.

There was also the conundrum brought to the profession by science centres and children's museums, mostly of the mid-twentieth century. Earlier in the century, these places had collected and displayed objects, but by mid-century children's museums and science centres were proliferating and creating new public experiences, using exhibition material that was built specifically for the purpose and omitting collections' objects altogether. How were these 'purpose-built' objects to be considered? They were three-dimensional, often unique, many times extremely well made, but they had no cognates in the outside world. Much of this exhibit material was built to demonstrate the activity and function of the 'real' (and now inactive) machinery sitting beside it.

The Adler Planetarium, applying to the AAM for accreditation, also caused the AAM to reconsider the definition of a museum. The 
planetarium's object was a machine that projected stars onto a ceiling. If institutions relied on such 'objects', were these places museums? Had the profession inadvertently crafted a definition of objects that was restricted to those things that were created elsewhere and were then transported to museums? That was not the case in art museums that commissioned site-specific work. Certainly the murals of the depression period applied directly to museum walls were accessionable works of art-an easy call! Portability, then, did not define objects.

In 1978, the Accreditation Commission of the AAM, citing these three different types of non-collections-based institutions (art centres, science and technology centres, and planetariums), wrote specific language for each type of museum and, by amending its definition of collections for each group, declared these types of organisations to be ... museums! They elaborated: 'The existence of collections and supporting exhibitions is considered desirable, but their absence is not disabling.....$^{3}$ In response, many museums set about creating more than one set of rules one for accessioned objects, and another for exhibitions material - and began to understand that the handleable material they used in their classes (their teaching collections) should be governed by a different set of criteria as well.

Nevertheless, there were often no easy distinctions between the handleablity of teaching collections' objects and those others deserving preservation. The Boston Children's Museum loan boxes, for example, created in the 1960s, contained easy-to-obtain material about Northeast Native Americans. But by the 1980s, the remaining material was retired from the loan boxes and accessioned into the collections because it was no longer obtainable and had become rare and valuable.

Even purpose-built 'environments' have, in cases such as the synagogue models in the Museum of the Diaspora in Tel Aviv, become so intriguing or are of such craftsmanship that they, decades later, become collections' objects themselves. So, too, have the exhibitions created by distinguished artists, such as parts of Charles and Ray Eames's exhibit Mathematica: A World of Numbers and Beyond.

Dioramas were often built for a museum exhibition hall in order to put objects (mostly animals) in context. These display techniques, which were considered a craft at the time they were created, were occasionally of such beauty, and displayed artistic conventions of realism (and seeming realism) so special, that today the original dioramas themselves have become 'objects', and many are subject to preservation, accession, and special display. The definition of objects suitable for collections has, therefore, expanded to include, in special cases, material built for the museum itself.

\section{WHAT IS REAL? IS THE EXPERIENCE THE OBJECT?}

In the nineteenth century, some museums had and displayed sculptural plaster castings and studies. The Louvre and other museums had rooms devoted to copies of famous sculptures that the museum did not own. The originals either remained in situ or were held by others. People came to see, study, and paint these reproductions. They were treated with the respect accorded the real thing. For a long time, museums and their publics have felt that though there were differences between the 'original' and reproductions, both had a place within their walls.

Similarly, reconstructed skeletons of dinosaurs have long appeared in museums. They usually are a combination of the bones of the species owned by the museums plus the casting of the missing bones from the same species owned by someone else. Sometimes museums point out which part is real and which is cast, but often they do not. 'Real', therefore, takes on new meaning. Curators recognise that the experience of seeing the whole skeleton is more 'real', and certainly more informative, than seeing only the authentic, unattached bones that do not add up to a complete or understandable image.

Likewise, multiples or limited editions were always considered 'real' as long as the intention of the artist was respected. Thus, the fact that Rodin and many others authorised 
the multiple production of some pieces did not seem to make each one any less real or less unique. The creation of additional, though still limited, copies, using the same etching plates, but after the death of the artist, caused more problems. But often, while acknowledging the facts of the edition, such works also hung in museums and, if the quality was good, were accessioned into their collections.

\section{IS THE IMAGE THE OBJECT?}

The twentieth century's invention of new technologies has made multiples the norm and made determining what is real and what that means much more difficult. While original prints of movies, for example, exist, it is the moving image that the public thinks of as the object rather than the master print of film. Questions of authenticity revolve around subsequent manipulation of the image (e.g. colonisation, cutting, or cropping) rather than the contents of any particular canister.

Printed editions with identical multiples are considered originals, and become more valuable, if signed; unsigned editions are considered less 'real' and certainly less valuable. In such cases one could say that the signature, rather than the image, becomes the object. Photographs printed by the photographer may be considered more real than those using the same negative but printed by someone else. With the invention of digital technology, many identical images can be reproduced at will without recourse to any negative at all. So the notion of authenticity (meaning singularity or uniqueness) becomes problematic as images indistinguishable from those in museums are easily available outside the museum. It is the artist's sensibility that produced the image. It is the image itself, therefore, that is the object.

\section{IS THE STORY THE OBJECT?}

Of the utilitarian objects of the twentieth century, most are manufactured in huge quantities and therefore could be termed 'examples'. Which of these objects to collect often then depends not upon the object itself but on an associated story that may render one of them unique or important.

The objects present in the death camps of the Holocaust were, in the main, created for use elsewhere. There is nothing unique in the physicality of a bowl that comes from Auschwitz-Birkenau. These bowls could have been purchased in shops that sold cheap tableware all over Germany at the time. However, when the visitor reads the label that says the bowl comes from Auschwitz, the viewer, knowing something about the Holocaust, transfers meaning to the object. Since there is nothing aside from the label that makes the bowl distinctive, it is not the bowl itself but its associated history that forms importance for the visitor.

\section{DOES THE CULTURAL CONTEXT MAKE THE OBJECT?}

As Foucault and many others have written, objects lose their meaning without the viewer's knowledge and acceptance of underlying aesthetic or cultural values. Without such knowledge, an object's reification even within its own society cannot be understood. Often the discomfort of novice visitors to art museums has to do with their lack of understanding of the cultural aesthetics that the art on display either challenges or affirms.

By accessioning or displaying objects, the creators of museums exhibitions are creating or enhancing these objects' value. Further, society's acceptance of the value of museums themselves likewise transfers value to their objects. When museums receive gifts or bequests from a major donor's holdings, they are inheriting — and then passing on - a set of value judgments from someone who is essentially hidden from the visitor's view. A particular aesthetic pervades such museums because of the collections they house and the collectors who gave the objects in the first place.

This issue of values determining choice comes into sharper focus when museums begin acquiring or presenting collections from cultures whose aesthetic might be different. 
When installing a show of African material in an American art museum, should the curator show pieces based on the values inherent in the producing culture (i.e., focusing on the objects that attain special aesthetic value within that culture), or should the curator pick objects that appeal more to the aesthetic of his or her own culture? This question, the source of much debate, arises when museums attempt to diversify their holdings to include works created by a foreign (or even an assimilated) culture quite different from that which produced the majority of their holdings. For example, the selection of which African or Latino art to accession or show has to do not with authenticity but with quality. The notion of quality has been sharply debated between the scholar within the museum and the peoples representing the culture of the maker. So the question becomes: who selects the objects and by what criteria?

In material created by Indigenous artists, the native community itself sometimes disagrees internally as to whether the material is native or belongs to a modern tradition that crosses cultural boundary lines. Some within the native population also argue about the birthright of the artist; blood quantum, traditional upbringing, and knowledge of the language sometimes have considerable bearing on whether artists and their creations are considered native. In such cases, the decision about what is quality work that should be housed in a museum may have little to do with the object itself and more to do with the genealogy of the producer.

\section{WHAT IF YOUR STORY HAS NO OBJECTS OR DOES NOT NEED THEM? IS THE ABSENCE OF OBJECTS THE OBJECT?}

Most collections were created by wealthy people who acquired things of interest and value to themselves. The everyday objects of non-valued or subjugated peoples were usually not collected. Often the people in the lowest economic strata could hardly wait to exchange their objects for those that were more valued, giving no thought, at the time, to the preser- vation of the discarded material. So it goes for most peoples during their most impoverished historical periods. Accordingly, their museums must choose among a narrow band of choices - do not tell that part of their history, recreate the artefacts and environments, or use interpretative techniques that do not rely on material evidence.

The Museum of the Diaspora in Israel, struggling with this issue more than twentyfive years ago, decided to tell the complete story of five thousand years of Jewish migration without using a single authentic artefact. It elected to create tableaux that reproduced physical surroundings in an illustrative manner based on scholarly research into pictorial and written documentation of all kinds. The museum did so because its collection could not accurately or comprehensively tell the story, and a presentation of settings that appeared 'like new' honoured the history of Jewish migration more than an assortment of haphazard authentic artefacts showing their age and wear. The experience, wholly fabricated but three-dimensional, became the object. It presented a good public experience, many argued, but still did not qualify as a 'museum'. Ultimately, this total re-creation was accepted as a highly distinguished museum. The Museum of the Diaspora also presented movies, photos, and recordings in a publicly accessible form, arguing that a comprehensive presentation required material that was nonartefactual.

The U.S. African-American and Native American communities have suggested, in the same vein, that their primary cultural transmission is accomplished through oral language, dance, and song - vehicles that are ephemeral. Their central artefacts, or objects, if you will, are not dimensional at all, and museums that wish to transmit the accuracy of such cultures, or display historical periods for which material evidence is not available, must learn to employ more diverse material. It may be the performance that is the object, for example. And the performance space might need to be indistinguishable from the exhibit 
hall. As museums struggle to do this, one begins to see videos of ceremonies and hear audio chanting. Such techniques, formerly thought of as augmentation rather than core interpretation, have increasingly taken on the role and function previously played by collection objects.

Even in museums like Cleveland's Rock and Roll Hall of Fame or the soon-to-beopened Experience Music Project, it is the sound and performance of the artists that is the artefact much more than the stationary guitar that, say, Jimi Hendrix once used. Indeed, musical instrument archives at the Boston Museum of Fine Arts and other places have long struggled with the proper presentation of their 'artefacts'. 'Silent musical instruments' approaches an oxymoron.

HOW IS THE OBJECT TO BE PRESERVED? IS THE OBJECT TO BE USED?

The museum, in accepting an object for its collection, takes on the responsibility for its care. In doing so, collections managers follow rules organised for the safety and long-term preservation of the objects. Climate control, access restrictions, and security systems are all issues of concern to those who care for objects. Institutions devoted to music or performance transform the notion of collections and certainly the notion of preservation, because while it is true that most things are preserved better when left alone, some musical instruments are not among them. They are preserved better if played, and so, for example at the Smithsonian's Museum of American History, they are.

Likewise, many native people have successfully argued that accessioned material should be used in the continuance of ceremony and tradition. Artefacts, rather than being relinquished to isolated preservation (and losing their usefulness), are stored in trust waiting for the time when they must again be used. In the 1980s, when native people from a specific clan or group asked for an object to be loaned for a short-term use, this was a radical notion for most natural history museums. That request now is more common and often accommodated. For example, at the end of the 1980s, the Dog Soldiers of the Northern Cheyenne requested their pipe, which the Smithsonian's National Museum of Natural History holds, and used it in their ceremonies, after which it was returned to the museum.

Now, native museums and, less commonly, some general museums that hold native material accept objects into their collections with the express understanding that they will be loaned out and used when needed. The notion of a museum as a storehouse in perpetuity has, in these instances, evolved into the museum as a revolving loan warehouse. A long-standing and easily understood example predates this relatively new development. The Crown Jewels of the British monarchy, which are displayed in the Tower of London, are worn by the monarch when he or she is crowned. And so it has been for many centuries.

\section{WHOSE RULES ARE USED FOR OBJECT CARE?}

There are other fundamental rules of collections that are successfully being challenged worldwide by native people's involvement. Collections care has been predicated on the basic notion that objects are inanimate. Though some objects were once alive, they now are no longer, and most had never been alive. Thus, collections-care policies proceeded from the assumption that objects should be preserved in the best manner possible, avoiding decay from elements, exposure, and use. Protective coverings and storage cases were designed to do just that. Extremes in the exposure to light and temperature, and all manner of pest infestation, were to be avoided. But when the museum was recognised to be neither the only nor the absolute arbiter of its material holdings, accommodation to the beliefs of the producers of the materials or their descendants became necessary.

These beliefs often included a lack of distinction between animate and inanimate. Thus, spirits, mana, fields of power, and life sources could live within an object regardless of the material from which it was made. And 
that being so, the care for these living things, it was argued, is, and should be, quite different from the care of dead or never alive things. So, for example, bubble wrap, while an excellent protector of objects, does not allow for breathing or 'singing and dancing at night'. Those working with native populations in good faith have come to respect native understanding of their own objects and now provide for the appropriate life of the object. Some objects need to be fed, some need to be protected from their enemies, some need to be isolated from menstruating women. Collections are no longer under the absolute province of the professional caregivers. Storage facilities that accommodate the native understanding of their objects require new architectural designs that allow for ceremony for some and isolation from the curious for others.

\section{WHO OWNS THE COLLECTIONS?}

This change in collections use and care alters the notion of the museum as owner of its collections and opens the door to multiple definitions of ownership. These new definitions have far-reaching implications. If tribal communities can determine the use, presentation, and care of objects 'owned' by museums, can the descendants of an artist? Can the victims or perpetrators of a war event? In the recent Smithsonian National Museum of Air and Space Enola Gay exhibition controversy, it was the veterans who flew the plane and their World War II associates who ultimately controlled the access to, presentation of, and interpretation of the object. Ownership or legal title to an object does not convey the simple, more absolute meaning it did when I began in the museum field.

The notion that if you buy something from a person who controlled it in the past, then it is yours to do with as you wish is clearly under redefinition in a number of fields. What constitutes clear title? Under what rules does stolen material need to be returned? What is stolen, in any case? Do the Holocaust victims' paintings and the Elgin Marbles have anything in common? The issue is so complex and varied that countries forge treaties to try to determine which items of their patrimony should be returned. Similarly, museums in countries like New Zealand, Canada, and Australia have developed accords that, in some cases, give dual ownership to collections. Museums and the native populations then jointly control the presentation, care, and even return of the objects, or museums give ownership to the native populations, who, in turn, allow the museum to hold the objects in trust. Ownership has developed a complex meaning.

\section{IF I OWN IT CAN I HAVE IT BACK, PLEASE?}

Some of this blurring of ownership began with native people maintaining that some items should not be in the hands of museums regardless of their history. That this would be claimed for human remains held in collections was easy to understand. Almost all cultures do something ceremonial and intentional with the remains of their people, which, in almost all instances, does not include leaving bodies for study in boxes on shelves. So when native people started to call for the return of their ancestors' remains, there was an intuitive understanding of the problem in most circles. This, however, did not make it any easier for the paleontologists and forensic curators whose life work had centred on the access to these bones, nor for the museum-goer whose favorite museum memories had to do with shrunken heads, mummies, or prehistoric human remains. The arguments that emanated from both sides were understandable and difficult to reconcile. It was a clear clash of world views and belief systems. To the curators it seemed that removal of human remains within museum collections would result in the unwarranted triumph of cultural tradition and emotionalism over scientific objectivity and the advancement of knowledge.

As it turned out, the Native American Grave Protection and Repatriation Act

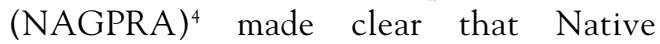
American tribes had rights to the return of their sacred material and to their ancestors' 
remains and associated grave goods, regardless of the method by which museums had acquired the material. However, the emptying of collections into native communities, as predicted by the most fearful, did not happen. Rather, museums and native communities, working together in good faith, moved into an easier and more collegial relationship, as between equals. In most cases, the objects returned are carefully chosen and returned with due solemnity. Some tribes have chosen to allow some forensic samples to be saved, or studied prior to reburial, and some have reinterred their ancestors in ways that could allow for future study should the native community wish it.

NAGPRA struck a new balance between the world view of most museums and their staff (which endorsed a rational and scientific model of discourse and allowed for access to as much information as could be gathered) and the spiritual interests of traditional native peoples. A variety of museum practices were broadened, and visitors began to see the interpretation of exhibitions changed to include multiple side-by-side explanations of the same objects. For example, Wolves, an exhibition created by the Science Museum of Minnesota, presented scientific data, native stories, conservation and hunting controversies, and physiological information together in an evenhanded way. An argument for multiple interpretations began to be heard in natural history museums whose comfort level in the past had not permitted the inclusion of spiritual information in formats other than anthropological myth.

\section{HOW OLD IS AN OBJECT?}

The scientific dating of artefacts used in religious practices often holds little relevance to the believers. When an object such as the Shroud of Turin, for example, is carbon dated and shown to be insufficiently old, the problem of writing its museum label becomes complex. An object held in Te Papa, the Museum of New Zealand, was returned to an iwi (tribe) that requested it, with all the solemnity and ceremony appropriate. So too went records of its age and material composition, at variance with beliefs held by the Maori people. But if, as the Maori believe, spirit or mana migrates from one piece to its replacement (rendering the successor indistinguishable from its more ancient equivalent), then what relevance is the fact that dates or materials are at variance? The object's cultural essence is as old as they say.

Similarly, when restoration of landmarks includes the replacement of their elements (as is routinely the case in Japanese shrines), the landmark is said to be dated from its inception even though no material part of it remains from that time. That does not upset us. So even something so seemingly rational and historical as dating is up for interpretation.

THE OBJECT IS OFF-LIMITS. IT IS NONE OF YOUR BUSINESS

Museums, even in their earliest incarnations as cabinets of curiosities, were available to all interested eyes or at least to those allowed to have access by the owners of the cabinets. In fact, part and parcel of conquest and subjugation was the access to interesting bits of the subjugated. This assumption that everything was fair game held currency for a long time. Though the notion of secret and sacred was also understood (for example, no one but the faithful could enter Mecca), this concept did not attach to museums nor to the holdings thereof. If a museum owned it, the visitors could see it if the curator/staff wished them to.

So it came as a surprise to some curators that contemporary native peoples began to make demands on museums to return not only human remains but material that was sacred and once secret. Accommodations negotiated between the museums and the native people sometimes led to agreements to leave the material in the museum but to limit viewing access. The notion that one people, the museum curators, would voluntarily limit their own and others' access to material owned by museums came initially as a shock to the museum system. But under the leadership of sympathetic museum and native people and, further, under the force of NAG- 


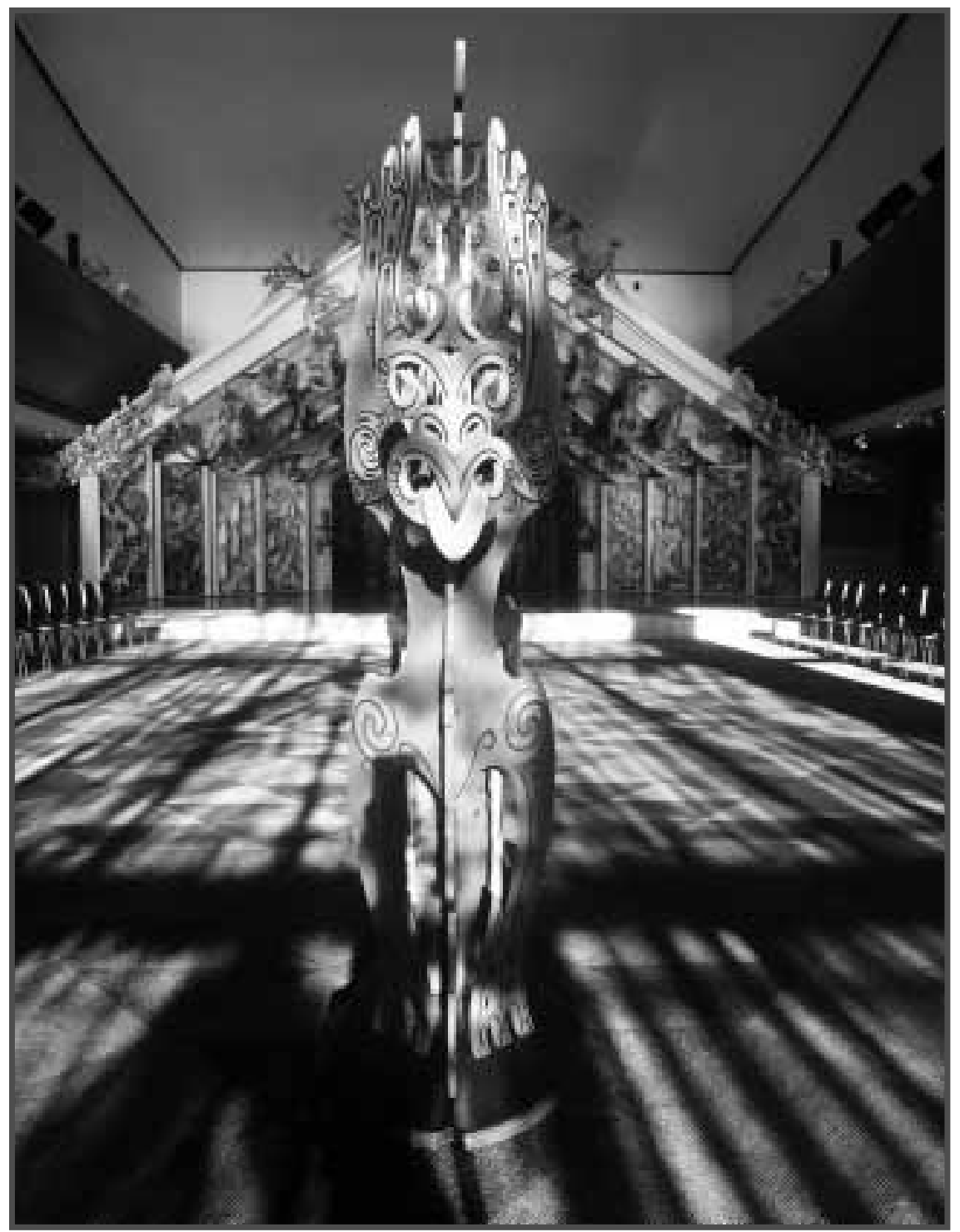

Te Marae, Courtesy Te Papa, Museum of New Zealand.

PRA, museums began to understand that all material was not to be made available to all interested parties.

It was the beginning of the 'It is none of your business' concept of museum objects. It held that the people most intimately concerned with and related to the material could determine the access to that material. In many cultures sacred ceremonies are open to all, and the objects in use are available for view in museum settings, but that too may change. For example, in Jewish tradition, Torahs once desecrated are supposed to be disposed of by burial in a prescribed manner. Yet some of these are available for view, most notably at the United State Holocaust Memorial Museum. There may come a time when such artefacts are petitioned to be removed for burial even though the statement they make is powerful. 
WHO SAYS ALL OBJECTS NEED TO BE PRESERVED

Ownership is not always an issue; sometimes it is the preservation of the object itself that needs examination. Museums have felt their most fundamental responsibility extended to the preservation of the object, yet in returning human remains to the earth, artefacts are being intentionally destroyed. That was difficult to reconcile for those trained in preservation. Even more difficult was the belief that not all things made by hand were intended to be preserved; perhaps some should be allowed to be destroyed. The Zuni war gods preserved by museums were returned to the Zuni tribe when it was successfully proven that these could only have been stolen from grave sites. But even more difficult was the Zuni's assertion that these objects were created to accompany the dead, and that preservation of them was therefore anathema. The war gods were returned to the Zuni, who watched over the gradual decay of these objects as they returned to the earth. In effect, the Zuni were entitled to destroy the objects that the museums had so carefully preserved.

The notion of preservation has, therefore, also been blurred. Museum personnel began to wrestle with the notion that all people do not hold preservation of all objects as a universal good. The Tibetan Lamas who create exquisite sand paintings only to destroy them later would certainly understand this.

\section{THE OBJECT SPEAKS}

I would be remiss if I did not also acknowledge the power of some objects to speak directly to the visitor, for example, in the sensual pleasure brought about by viewing unique original objects of spectacular beauty. But the notion that objects, per se, can communicate directly and meaningfully is under much scrutiny. The academicians of material culture, anthropology, history, and other fields are engaged in parsing the ways in which humans decode objects in order to figure out what information is intrinsic to the object itself, what requires associated knowledge gleaned from another source, and what is embedded in cultural tradition.

In some ways, it is because of this parallel contemporary inquiry into the 'vocabulary' of objects that I can inquire into the object's changing role in the definition of museums.

WHAT ARE MUSEUMS IF THEY ARE LESS OBJECTBASED?

Museum staff intuitively understand that museums are important - an understanding that the public shares. However, especially for the public, this understanding does not always revolve around the objects, though objects are, like props, essential to most museums' purposes: making an implicit thesis visible and tangible. The nature of the thesis can range from explanation of the past to advocacy for a contemporary viewpoint to indication of possible future directions - in each case through a medium that presents a story in sensory form.

Museums will remain responsible for the care of the objects they house and collect, but the notion of responsibility will be, and has already been, broadened to include shared ownership, appropriate use, and, potentially, removal and return.

The foundational definition of museums will, in the long run, I believe, arise not from objects, but from 'place' and 'storytelling in tangible sensory form', where citizenry can congregate in a spirit of cross-generational inclusivity and inquiry into the memory of our past, a forum for our present, and aspirations for our future.

Coming back to definitions, the current definition of museums used by the Accreditation Program of the AAM encompasses all museums and no longer separates them by categories. Museums, in this definition, “... present regularly scheduled programs and exhibits that use and interpret objects for the public according to accepted standards; have a formal and appropriate program of documentation, care, and use of collections and/or tangible objects ..."

For the visitor, it is the experience of simultaneously being in a social and often celebratory space while focusing on a multi- 
sensory experience that makes a museum effective. Virtual experiences in the privacy of one's home may be enlightening but, I think, are not part of the civilising experience that museums provide. It is the very materiality of the building, the importance of the architecture, and the prominence that cities give to museum location that together make for the august place that museums hold. Congregant space will, I believe, remain a necessary ingredient of the museum's work.

The objects that today's museums responsibly care for, protect, and cherish will remain central to their presentations. But the definition of 'objectness' will be broad and allow for every possible method of storymaking. These more broadly defined objects range from hard evidence to mere props and ephemera. I hope I have shown that objects are certainly not exclusively real nor even necessarily 'tangible' (even though the AAM uses that word). For it is the story told, the message given, and the ability of social groups to experience it together that provide the essential ingredients of making a museum important.

Museums are social-service providers (not always by doing direct social-service work, though many do that), because they are spaces belonging to the citizenry at large, expounding on ideas that inform and stir the population to contemplate and occasionally to act.

Museums are not unique in their work. Rather, they share a common purpose with a host of other institutions. We need museums and their siblings because we need collective history set in congregant locations in order to remain civilised. Societies build these institutions because they authenticate the social contract. They are collective evidence that we were here.

\section{ELAINE HEUMANN GURIAN}

This paper first appeared in Daedalus, 'America's Museums' issue, Vol 128, No. 3, Summer 1999, pp. 163-183. Reproduced by permission.

\section{Endnotes}

1 'For the purposes of the accreditation program of the AAM, a museum is defined as an organized and permanent non-profit institution, essentially educational or aesthetic in purpose, with professional staff, which owns and utilizes tangible objects, cares for them, and exhibits them to the public on some regular schedule.' American Association of Museums, Museum Accreditation: Professional Standards (Washington, D.C.: American Association of Museums, 1973), p. 8.

2 '... owns and utilizes tangible things animate and inanimate.' Museum Accreditation: Professional Standards, p. 9.

3 An art centre 'utilizes borrowed art objects, cares for them and maintains responsibility to their owners ... [its] primary function is to plan and carry out exhibitions.' American Association of Museums, Museum Accreditation: Professional Standards, p.12. A science and technology centre '... maintains and utilizes exhibits and/or objects for the presentation and interpretation of scientific and technological knowledge.... These serve primarily as tools for communicating what is known of the subject matter. ...' American Association of Museums, Museum Accreditation: Professional Standards, p. 12. A planetarium's '. . . principal function is to provide educational information on astronomy and related sciences through lectures and demonstrations.' American Association of Museums, Museum Accreditation .... p. 11.

4 Native American Grave Protection and Repatriation Act (25 U.S.C. 3002).

5 American Association of Museums, A Higher Standard: The Museum Accreditation Handbook (Washington, D.C.: American Association of Museums, 1997), p. 20. 